Palabras clave/ Vivienda, preservación, ciudad, sociedad.

$\Delta$ Keywords/ Housing, conservation, city. society

$\Delta$ Recepción/ 9 mayo 2017

$\Delta$ Aceptación/ 10 noviembre 2017

\title{
El enfoque diluido: Salvaguardar el patrimonio doméstico de Necochea-Quequén desde el binomio bien-usuario ${ }^{1}$
}

\section{The diluted approach: Safeguarding Necochea-Quequén's domestic heritage based on the binomial property-user ${ }^{1}$}

\author{
Lorena Sánchez \\ Arquitecta, Universidad Nacional de Mar del \\ Plata, Argentina \\ Doctora en Arquitectura, Universidad de \\ Mendoza, Argentina. \\ Magíster en Intervención del Patrimonio \\ Arquitectónico y Urbano, Universidad Nacional \\ de Mar del Plata, Argentina. \\ Investigadora adjunta, Consejo Nacional de \\ Investigaciones Científicas y Técnicas, Argentina \\ Docente e investigadora, Facultad de \\ Arquitectura, Urbanismo y Diseño de la \\ Universidad Nacional de Mar del Plata, \\ Argentina.
}

lorenasanchezarq@yahoo.com.ar

RESUMEN/ Salvaguardar el patrimonio doméstico de las ciudades intermedias latinoamericanas constituye un reto inconcluso. En este reto, la comprensión de las relaciones entre los bienes y sus usuarios suele reconocerse como clave sustancial para encontrar respuestas. Sin embargo, este enfoque se diluye, a menudo, en las investigaciones y las consecuentes directrices proteccionistas. Por ello, en el presente artículo se aborda este camino dentro de un territorio específico y un marco proteccionista local, mediante el análisis de la concientización usuaria de los bienes domésticopatrimoniales de Necochea-Quequén. Desde variables histórico-arquitectónicas y sociales, se aborda esta aglomeración intermedia que ostenta múltiples complejidades dentro de la provincia de Buenos Aires, Argentina. ABSTRACT/ To safeguard the domestic heritage of middle-sized Latin American cities constitutes a pending challenge. In this difficult task, to understand the relationship between properties and their users is critical in order to come up with answers. However, such an approach sometimes ends up washed away by many researches and ensuing protectionist guidelines. For this reason, this article addresses this approach within a specific territory and a local protectionist framework by means of an analysis of user awareness of domestic-heritage properties in NecocheaQuequén. This intermediate agglomeration that features multiple complexities within the Province of Buenos Aires, Argentina, is approached from historical-architectural and social variables.

\section{INTRODUCCIÓN.} las viviendas significativas de cada ciudad, constituye un reto inconcluso Este desafío resulta relevante en las urbes latinoamericanas, en las cuales se acrecientan los conflictos preservacionistas debido a sus dinámicas socioeconómicas y, en paralelo, se vislumbran oportunidades en los intersticios de los vacíos patrimoniales que suelen manifestar. En esta dualidad, importan no solo las caracterizaciones cuantitativas que definen a las ciudades intermedias dentro de un rango menor al millón de habitantes, sino que son sustanciales los análisis cualitativos que permiten interpretarlas mediante los itinerarios vitales, las identidades y los imaginarios de los ciudadanos (Hábitat III 2015; Gravano, Silva y Boggi 2016). En estas ciudades existen diferentes tipos de viviendas típicas que testimonian los procesos sociohistóricos y, por ende. ameritan su protección (Waisman 1992).

Si bien sus cuantías son contundentes, las dificultades para ampararlas son numerosas Su carácter privado, las economías débiles, la envergadura de los parques construidos, las presiones inmobiliarias, las normativas proteccionistas no aplicadas e incluso inexistentes y las discontinuidades en las prácticas, son solo algunos de los problemas posibles.

Diversas experiencias desarrolladas para preservar este legado, afirman que es posible obtener respuestas mediante un enfoque centrado en las relaciones entre los habitantes y sus viviendas. Esta mirada comprende que los usuarios, propietarios o inquilinos, son los que poseen la principal autoridad práctica para consumar transformaciones y permanencias. Por ello, propone que al entender las dinámicas sociomateriales, resulta factible emprender estrategias progresivas que activen retroalimentaciones preservacionistas a largo plazo (Carrión Mena 2000; Delgadillo 2011; Gutiérrez 2003). 
En este sentido, y desde una perspectiva internacional, es necesario mencionar las señeras tareas realizadas en Bolonia en 1969 ya que por primera vez se vinculó la defensa de un centro histórico con las aspiraciones de los sectores populares en relación a sus hogares. Desde entonces, las experiencias europeas han avanzado, como lo obrado a partir de 1990 para el tratamiento de los bienes tradicionales mediterráneos. Estos aprendizajes, a su vez, han constituido referentes para la ideación de propuestas adecuadas al ámbito latinoamericano, como las prácticas perfeccionadas desde 1980 en Brasil y en Argentina, sumadas a las de Bolivia, México y Ecuador, entre otros países Dentro de estas experiencias, resulta relevante poner el foco en una de sus claves comunes: la concientización patrimonial. La concepción de la concientización posee sus más destacadas raíces en las intersecciones de la filosofía, la educación, la sociología y la psicología. Desde las visiones de Freire (1975) hasta las de Sennet (2009 y 2012) y Bauman (2013), la concientización se asocia a la transformación de las estructuras, la amalgama entre la teoría y la práctica, la retroalimentación hacia la acción desde el sentimiento, el pensamiento y la voluntad como partes integrantes de un mismo proceso. En la apropiación patrimonial de esta noción, escasamente trabajada y cuyas alusiones específicas se revistan desde 1990 en el ámbito argentino, se comprende que la conciencia implica la aceptación emocional -sentir- y racional -pensar- de los valores heredados, mientras que la concientización avanza sobre acciones concretas -hacerpara alcanzar la preservación (Orueta 1990; Zingoni 2003).

Si bien es cada vez más frecuente encontrar rasgos analíticos asociados a este enfoque, suele ocurrir que se diluyen en la mayor parte de las investigaciones y las consecuentes directrices preservacionistas, en especial las originadas desde las esferas estatales. En Argentina, a modo de ejemplo, esta problemática acontece en casi la totalidad de las ciudades intermedias de la provincia de Buenos Aires, al sur del río Salado. En estas urbes, no solo se evidencia un escaso accionar para proteger áreas patrimoniales, las que permitirían el resguardo de este legado contextual, sino que las definiciones de salvaguarda pocas veces se asientan en indagaciones sobre el binomio bien-usuario (Sánchez 2014). Es habitual verificar que si se considera

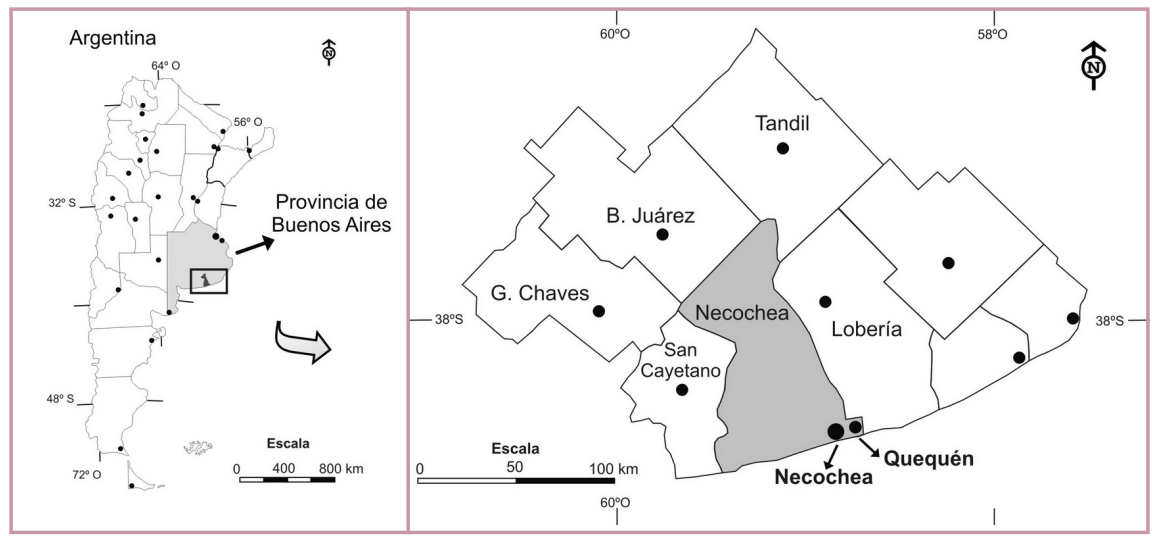

Figura 1. Ubicación de Necochea-Quequén (fuente: Elaboración propia). a los usuarios, el acercamiento se basa, principalmente, en datos cuantitativos, mientras que en los casos en los que se gestionan formas participativas, los aportes recogidos suelen disiparse dentro de planes y normativas.

Por ello, en este artículo se aborda el análisis de la concientización usuaria residencial-patrimonial, desde variables histórico-arquitectónicas y sociales en Necochea-Quequén. Esta aglomeración intermedia bonaerense, que ostenta fragmentos mediterráneos y costeros en debate, resulta relevante para explorar el

NECOCHEA-QUEQUÉN Y SUS BIENES DOMÉSTICOS.

se compone por dos núcleos separados por el río Quequén, unidos económica y políticamente mediante un decreto de 1979. Ese año Quequén fue deslindada del Partido ${ }^{2}$ de Lobería y anexada al Partido de Necochea y su ciudad cabecera, debido, entre otros factores, a la necesidad de movilizar la producción ganadera del sector a través de su puerto. Con conflictos desde entonces, constituye una aglomeración policéntrica y multifuncional sobre el frente marítimo atlántico (figura 1 e imagen 1). Así,

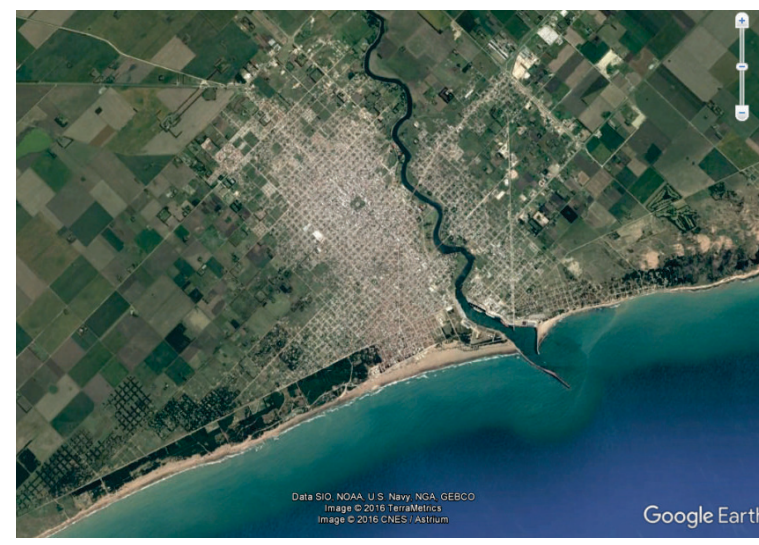

Imagen 1. Vista aérea de Necochea-Quequén (fuente: Google Earth 2016). 
Necochea-Quequén condensa tres polos de actividades, poblaciones y paisajes urbanos diferenciados: el centro histórico y la villa balnearia necochense, junto con el enclave portuario-industrial quequense.

Al igual que otras ciudades al sur del río Salado de la provincia de Buenos Aires, ambos núcleos son fundados en el siglo XIX, y la primera mitad del siglo XX resulta esencial en sus desarrollos. Quequén nace en el Partido de Lobería y se funda en 1854. Necochea, cabecera del Partido homónimo, se funda posteriormente en 1881. Las actividades balnearias germinaron en ambos núcleos a fines del siglo XIX y prosperaron con diferente ímpetu durante el siglo XX. El sector quequense, si bien fue precursor en el impulso balneario, gradualmente se particularizó por su sesgo productivo portuario-industrial. En este sentido, fue primordial su puerto de ultramar, que comenzó a operar en 1922. Necochea, en cambio, progresivamente se inclinó por las actividades balnearias, en estrecha relación con lo acontecido en la cercana ciudad de Mar del Plata y su temprana caracterización como ícono vacacional de las élites de Buenos Aires. Así, el sector necochense afrontó gran parte de su identidad mediante el ocio estival, originariamente deslindado de su centro fundacional (FAUD-UNMdP 1997; Merlotto, Piccolo y Bértola 2012; Municipalidad 2006 y 2008)

Las diferentes actividades socioeconómicas forjaron trazas y tejidos que definieron disímiles paisajes residenciales, en especial en el fragmento necochense. En su centro histórico sobrevivieron casas 'chorizo' (en adelante 'casas') originadas en los albores de su planificación urbana, mientras que en su villa balnearia se destacaron los chalets, particularmente los 'estilo Mar del Plata', surgidos sobre mediados del siglo XX (en adelante 'chalets') (figura 2)

Las casas prosperaron en Argentina sobre fines del siglo XIX y principios del XX. Se multiplicaron como respuesta a las necesidades habitacionales asociadas al crecimiento poblacional inmigratorio, primordialmente español e italiano. Su diseño ofreció a las entonces familias extendidas, una opción para alcanzar la vivienda propia en los pequeños lotes urbanos. Necochea no fue la excepción, y múltiples casas todavía distinguen el paisaje de su centro pampeano mediante

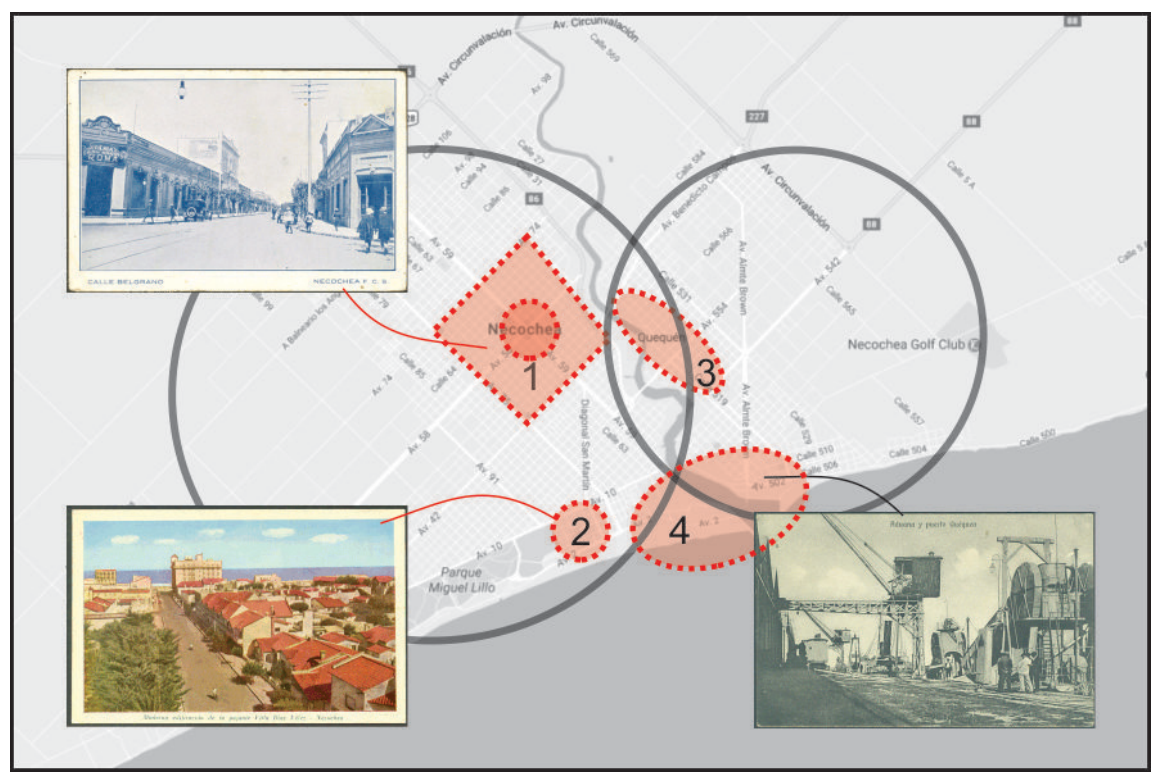

Figura 2. Núcleos primigenios de crecimiento: 1) y 2) centro fundacional y villa balnearia necochense, 3) iniciación quequense y 4) puerto (fuente: Elaboración propia sobre base planimétrica de Google y postales de colección privada).

las fachadas planas apoyadas sobre las líneas municipales (aunque existen del tipo retiradas). Generalmente de un piso y entre medianeras, su planta constituyó el sello tipológico mediante la disposición de tres ejes alineados, formados por habitaciones continuas, galerías y patios con diferentes jerarquías. Asimismo, el diseño de cuartos 'corridos' originó su popular nombre 'chorizo', en alusión a la ristra de embutidos consumidos en el país (figura 3).

Los chalets se originaron en la ciudad homónima. Allí surgieron, a principios del siglo XX, primitivas villas y chalets monumentales, inscriptos en las corrientes pintoresquistas europeas, pertenecientes a los grupos de élite de Buenos Aires. Los pequeños chalets, en cambio, prosperaron entre 1930 y 1950 como traducciones simbólicas y materiales de esos primeros exponentes, en respuesta a las necesidades de nuevos sectores sociales medios y un renovado espectro turístico. En Necochea, estos chalets se re-tradujeron como emblemas del veraneo. Construidos entre medianeras y con perímetro 0 semiperímetro libre, aún caracterizan su paisaje costero a través de las fachadas quebradas, retiradas de las líneas municipales mediante pequeños jardines, trabajadas con determinados materiales y técnicas (como el revestimiento de piedra
'Mar del Plata' que contribuyó con su nombre popular) (figura 4).

En cuanto al marco de preservación de esta herencia doméstica por parte de las entidades municipales, NecocheaQuequén posee ordenanzas que amparan principalmente bienes puntuales, con recientes desarrollos que aspiran a considerar los entornos urbanos. Sin oficinas específicas municipales que hayan perdurado, la Asociación Patrimonio Necochea, no gubernamental, es la que ha dinamizado las principales propuestas preservacionistas (Méndez 2004). Esta situación, sumada a la realidad territorialmente atomizada entre el desarrollo de la población estable y la estacional-estival, añade múltiples dificultades para proteger los

ABORDAJE. $\mid$ | abordaje de las variables histórico-arquitectónicas y sociales requirió de estrategias microanalíticas originales. Se trabajó desde una concepción de la investigación principalmente cualitativa, mediante el cruce de relevamientos in situ con el análisis de planimetrías, bibliografía y fotografías, la realización de entrevistas abiertas a informantes clave y de encuestas semiestructuradas de opinión.

Dentro del fragmento necochense seleccionado según el análisis histórico 
urbano y arquitectónico realizado, se relevaron 97 manzanas, 77 en el centro histórico y 20 en la Villa Balnearia, donde se identificaron 176 casas y 144 chalets. De esa totalidad de inmuebles, en el centro histórico se verificó la prevalencia de casas (175) en relación con la supervivencia de chalets (68). En forma inversa, en la Villa Balnearia se verificó la superioridad de chalets (76) en relación con la presencia de casas (1). De esta forma, se privilegió el análisis de las casas en el centro fundacional y de los chalets en la Villa Balnearia. De acuerdo con criterios cuali-cuantitativos relacionados con la cantidad y el estado de las viviendas por manzana, se seleccionaron tres microsectores para su análisis en profundidad: dos en el área central, con una totalidad de 12 manzanas y 56 casas, y uno en el fragmento balneario, formado por 3 manzanas y 35 chalets (figuras 5 y 6 ). En estos microsectores se trabajaron las relaciones sociomateriales desde la interpretación de las fuentes mencionadas y, en particular, a través de la indagación del estado de concientización de los usuarios mediante la triada presentada en la introducción. Paralelo se realizó una encuesta semiestructurada de opinión, domiciliaria, organizada en tres grupos de preguntas asociadas a los tres ejes de la concientización patrimonial: sentir, pensar y hacer.

En relación con el sentir, se exploró el estado de apropiación del hábitat-habitar (se examinó la antigüedad de permanencia en cada sector, el gusto por vivir allí, la antigüedad de permanencia en la vivienda, sus modos de obtención y el gusto por vivir en cada tipo). Sobre el pensar, se estudió el estado de conocimiento patrimonial de las viviendas (se preguntó por la identificación de su lugar más significativo, la consideración patrimonial, el reconocimiento de sus valores -históricos, arquitectónicos, urbanos u otros- y el interés por su preservación). En relación con el hacer, se examinó la disposición para actuar en la preservación residencial (se examinó el conocimiento de las posibles ayudas municipales, la ejecución de refacciones/reformas, el interés por participar en actividades preservacionistas -con un espectro de posibilidades para las respuestas afirmativas, como reuniones con usuarios, charlas con especialistas,

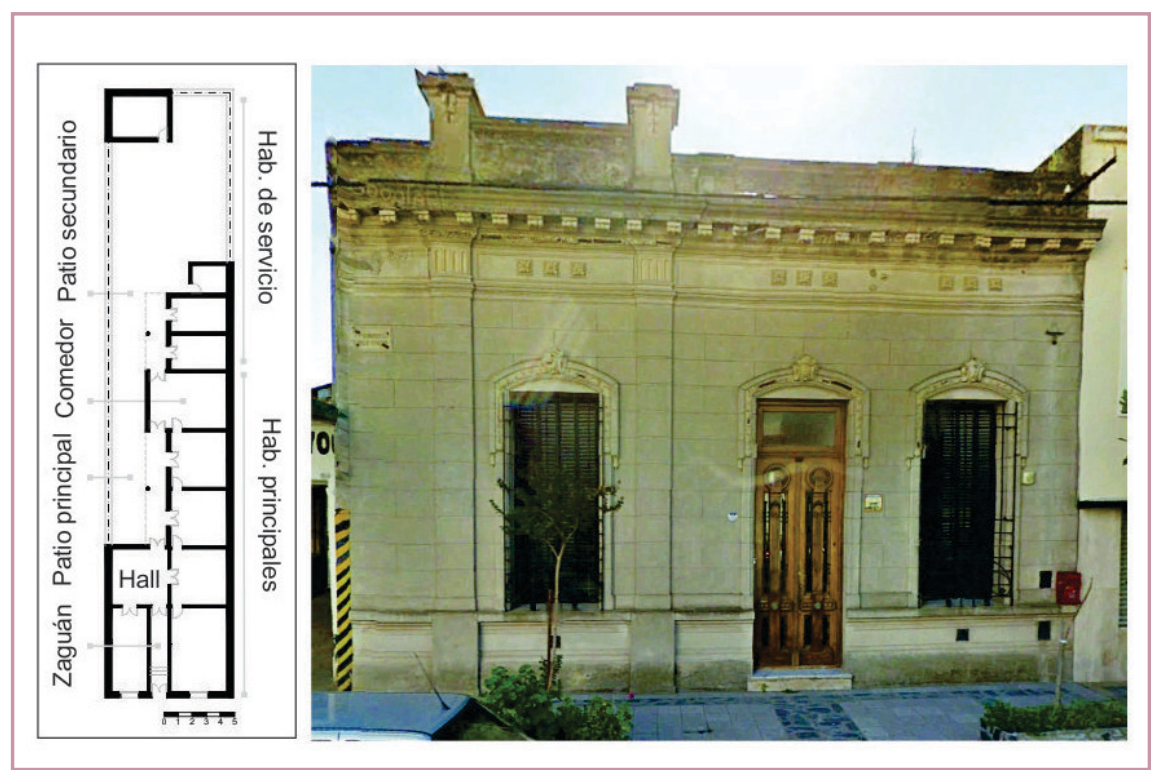

Figura 3. Casas: planta típica y caso necochense (fuente: Composición sobre base planimétrica de Google y postales de colección privada).

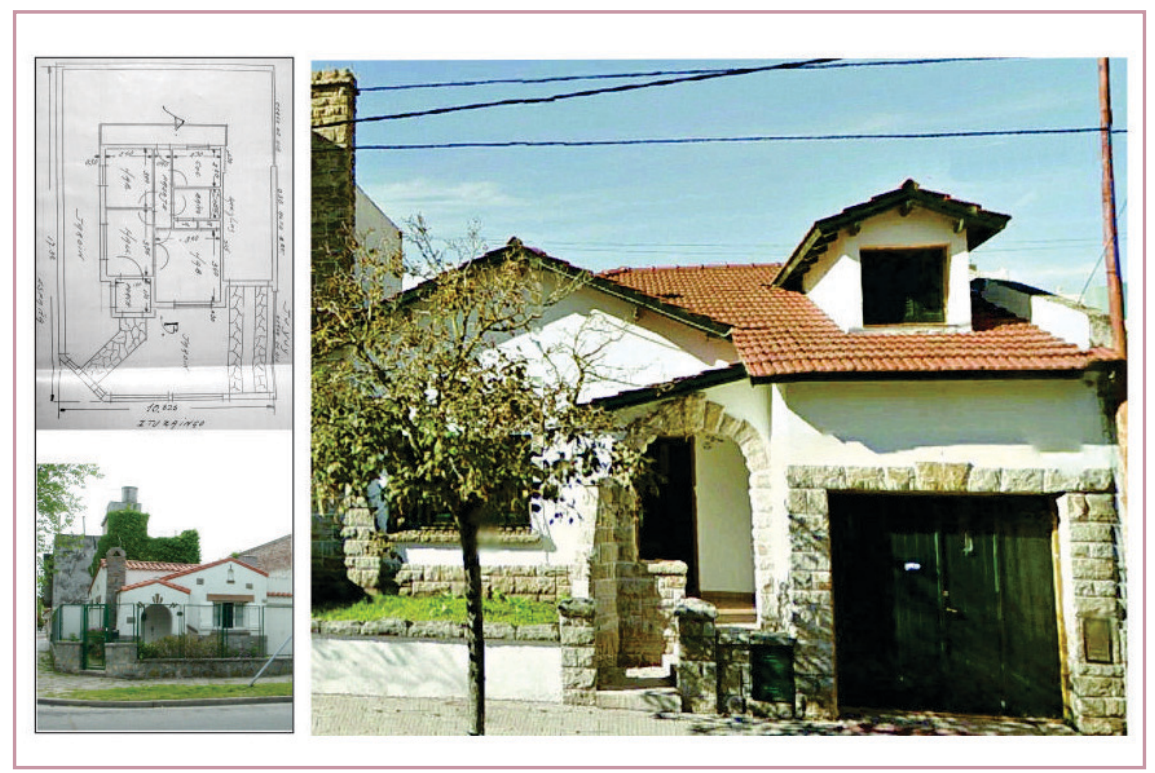

Figura 4. Chalets: planta/fotografía caso marplatense y fotografía caso necochense (fuente: Composición y fotografía de la autora).

concursos y juegos temáticos- y las

preferencias por diferentes medios para

recibir e intercambiar información temática -boletines/revistas, diarios, medios digitales u otros-). Finalmente, se diagramaron y cruzaron los datos obtenidos mediante matrices sintesis 
Figura 5. Casas: relevamiento y selección de fuente: Composición y fotografio dro hatora.
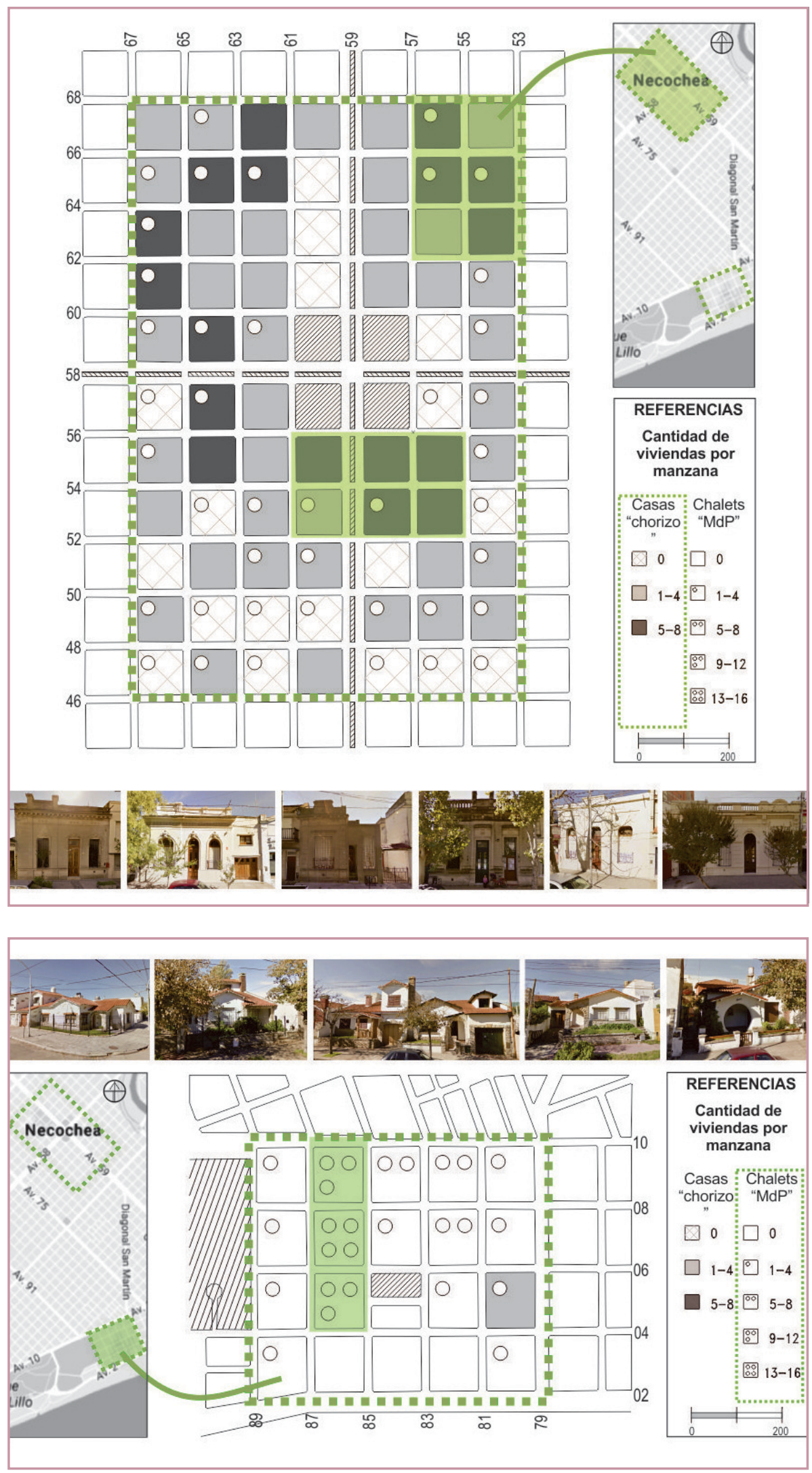
RESULTADOS. En forma sintética,

los resultados exhibieron una mediana antigüedad de permanencia en ambos sectores, con 30 años o más de asiento. En el sector costero, en paralelo, se destacó una permanencia de 10 años o menos de antigüedad. El gusto por vivir en cada fragmento fue positivo en casi su totalidad, principalmente argumentado mediante sus características geográfico-funcionales (gusto por playa-mar y por centro cívicocomercial-recreativo). Con respecto a la antigüedad de permanencia en las viviendas, si bien los resultados se asemejaron a la permanencia en el sector, se evidenció un recambio habitacional significativo ya que en ambos casos se destacaron las estadías de 10 años o menos de antigüedad. Así, se manifestó una dinámica de movilidades residenciales mayoritaria dentro de cada sector, con mayores persistencias dentro de las mismas viviendas en el fragmento mediterráneo. En cuanto a los modos de obtención de la vivienda, se destacó una mayoría de compras de casas, cercanas a las herencias, mientras que las herencias dominaron las tenencias de los chalets. Los alquileres, minoritarios, fueron mayores en el fragmento costero. De esta forma, se expresó un recambio residencial principalmente generacional de tipo familiar en ambos sectores. Con respecto al gusto por vivir en la vivienda y en estrecha relación con el ítem anterior, en los dos casos casi la totalidad de los usuarios declaró un afecto vivencial y enunció en forma positiva la amplitud de los cuartos y la ubicación urbana. En especial, insistieron en el apego ligado a las casas y en el disfrute del jardín asociado a los chalets. Desde el pensar, la identificación del lugar más significativo de la vivienda coincidió en ambos fragmentos: el estar/living. En las casas, en segunda instancia, fueron relevantes las elecciones del comedor y la cocina. Los usuarios de los chalets argumentaron razones relacionadas con el ocio doméstico y la recepción de visitas, algo usual en este tipo de viviendas costeras. En el caso de las casas, se esgrimieron razones ligadas a la cercanía con los patios y su luminosidad, mientras que el comedor y la cocina se eligieron por ser espacios de reunión familiar. Es notorio que no se subrayaran aquellos sitios que distinguen a las viviendas, como los patios de las casas o los frentes de los chalets. En ambos fragmentos, asimismo, fue mayoritaria la consideración patrimonial de las viviendas. Las principales explicaciones coincidieron en aspectos relacionados con la antigüedad. En el caso de los chalets, se sumaron descripciones basadas en la identidad y tradición de la villa balnearia e incluso se mencionó como cuantía su similitud con los chalets marplatenses. En las casas, las argumentaciones agregaron a la tipicidad como aspecto estimable. En contraposición, es interesante mencionar que la minoría que no las consideró valiosas, alegó que su carácter típico les 'quitaba' identidad. En cuanto al reconocimiento de los valores de las viviendas, en los dos casos se precisaron en similar medida las cualidades históricas, arquitectónicas y urbanas. Las jerarquías fueron levemente diferentes, mientras que para las casas predominaron los valores históricos seguidos de menciones afectivas, para los chalets se acentuaron los aspectos afectivos seguidos por cuantías arquitectónicas y urbanas. Así, los modos de obtención de las viviendas anteriormente enunciados, se manifestaron especialmente en esta expresión afectiva. El interés por la preservación de las viviendas fue mayoritario. En especial, los usuarios de las casas declararon su interés por salvaguardar la antigüedad y la calidad arquitectónica, mientras que los usuarios de los chalets mostraron interés por resguardar el 'panorama' villa-barrio.

Finalmente desde el hacer, se reveló un casi total desconocimiento de las ayudas municipales existentes. Con respecto a la realización de reformas en las viviendas, prácticamente la totalidad de los usuarios declararon haberlas realizado en mayor o menor medida. En paralelo, agregaron que eran necesarias nuevas intervenciones. Las más radicales operaron en el legado más antiguo, las casas, con preeminencia de modificaciones interiores (creaciones, divisiones y uniones de cuartos, bajadas de cielorrasos, techados de patios), modificaciones de cubiertas y renovaciones de baños/cocinas en segundo orden. En algunos casos, se especificó la eliminación de aljibes y palmeras originarias. En los chalets, las principales reformas se explicaron asociadas a las instalaciones y a la creación de nuevas habitaciones, seguidas por la renovación de baños.

La disposición para participar en actividades preservacionistas fue disímil en ambos fragmentos. La mayoría de los usuarios de las casas no se manifestó dispuesta, mientras que la mayoría de los usuarios de los chalets sí lo hizo. Dentro de las actividades preferidas se coincidió en la elección de charlas con especialistas y reuniones con usuarios. En cuanto a la mayoría de desinteresados dentro del fragmento mediterráneo, la apatía y la falta de tiempo fueron las argumentaciones más utilizadas. Al indagar sobre los diferentes medios para recibir e intercambiar información patrimonial, casi la totalidad de los usuarios se mostró atraída por los medios digitales-web. Aun así, a una segunda mayoría de usuarios de chalets no le interesó intercambiar información patrimonial en ningún formato/medio. En cuanto a los usuarios de las casas, el segundo lugar de preferencia fue ocupado por los diarios locales. Es interesante indicar que en ambos casos, aunque minoritariamente, se agregó un medio que no se había incluido: el correo postal. Los boletines y las revistas fueron los menos seleccionados. 


\section{Concentrar el enfoque.}

Necochea-Quequén constituye una aglomeración compleja originada por una unión decretada que presenta tensiones hasta la actualidad. En el sector necochense explorado, sus casas dentro del centro histórico y sus chalets dentro de la villa balnearia, han pervivido en un frági marco proteccionista.

Al analizar el grado de concientización usuaria residencial-patrimonial, fue posible reconocer: a) un sentir maduro por ambos fragmentos territoriales y sus viviendas características; b) un pensar en proceso donde se registran algunos de los atributos de cada tipología; y c) un hacer inmaduro en ambos sectores, particularmente notorio en el fragmento mediterráneo. En sintesis, se registra una óptima apropiación de ambos sectores y sus principales tipos de vivienda, un débil conocimiento de las cualidades patrimoniales, y una conflictiva acción y disposición usuaria para preservar los bienes.

Por ello, y con foco en el detalle de los resultados alcanzados, es urgente fortalecer el pensar y el hacer para avanzar en la conciencia patrimonial y alcanzar el ciclo de la concientización. Las debilidades expuestas en el hacer se encadenan a los trances entre los eslabones referidos al sentir y, en especial, al pensar. Las ayudas que se conciban podrán ser implementadas mediante la generación de nuevas áreas municipales, a través de la entidad patrimonialista no gubernamental vigente o bien, desde otras iniciativas sociales, grupales o individuales.
Reflexionar sobre la preservación del patrimonio doméstico desde una perspectiva en la que se amalgama el sentir-pensar-hacer usuario y cada marco proteccionista local, en un territorio específico como el necochense, acercó respuestas acerca de las necesidades y las posibilidades para direccionar lineamientos hacia un resguardo activo. Este camino poco transitado dentro de las urgencias latinoamericanas, proporciona un enfoque concreto factible de ser apropiado por otras realidades sociomateriales en ciudades de complejas dinámicas de cambio, y así, viabiliza nuevos horizontes para encontrar renovadas soluciones al reto de la salvaguarda doméstica.

\section{REFERENCIAS}

Bauman, Z. 2013. La cultura en el mundo de la modernidad líauida Buenos Aires: Fondo de Culture Económica.

Carrión, F. (Ed.), 2000. Desarrollo cultural y gestión en Centros Históricos. Quito: FLACSO Ecuador. Delgadillo, V. 2011. Patrimonio histórico y tugurios: las politicas habitacionales y de recuperación de los centros históricos de Buenos Aires, ciudad de México y Quito. México: UACM. FAUD-UNMdP, 1997. Habitar Necochea-Quequén. Mar del Plata: Programa Arraigo-FAUD-UNMdP. Freire, P., 1975. Acción cultural para la libertad. Buenos Aires: La Aurora.

Gravano. A.. Silva, A. y Boggi, S. (Eds.), 2016. Ciudades vividas. Sistemas e imaginarios de las ciudades medias bonaerenses. Buenos Aires: Café de las Ciudades.

Gutiérrez, R., 2003. "Transferencias, creatividad y rutina en los centros históricos de Iberoamérica." En Novacovsky. A. y Viñuales. G. (Eds.). Textos de cátedra. Maestría GIPAU (Vol. 2).

Mar del Plata: FAUD- UNMdP, 33-50

Hábitat III, 2015. Ciudades intermedias: crecimiento y renovación urbana. Cuenca: ONU-Hábitat. Méndez, M., 2004. Los caminos del Patrimonio Arquitectónico-Urbano (Tesis para optar al grado de Magister Maestria GIPAU-UNMdP)
Merlotto, A. Piccolo M y Bértola, G. 2012 "Crecimiento urbano y cambios del uso/cobertura del suelo en las ciudades de Necochea y Quequén." Revista de Geografía Norte Grande, 53, 159-176. Municipalidad de Necochea, 2006-2008. Plan Urbano Ambienta/ del Partido de Necochea. Necochea: Municipalidad-BID- Ministerio de Economí.

Orueta, M., 1990. "Concientización, difusión y medios de comunicación para la defensa del patrimonio." V Congreso Nacional de Preservación del Patrimonio Arquitectónico y Urbano, 24 al 28 de Octubre, Mar de Plata, Buenos Aires.

Sánchez, L., 2014. "La concientización usuaria del patrimonio modesto. Sentir, pensar y hacer en dos ciudades intermedias argentinas: Mar del Plata y Tandil." RevistArquis, 6, 1-15.

Sennett, R., 2009. El Artesano. Barcelona: Anagrama.

Sennett, R., 2012. Juntos. Barcelona: Anagrama.

Waisman, M., 1992. El patrimonio modesto. Bogotá: Cuadernos Escala.

Zingoni, J., 2003. "Gestión del patrimonio arquitectónico y urbano." En Novacovsky, A. y Viñuales, G. (Eds.), Textos de cátedra. Maestría GIPAU (Vol. 2). Mar del Plata: FAUD- UNMdP. 175-203. 